\title{
ChemCatChem
}

Supporting Information

\section{Bifunctional Intimacy and its Interplay with Metal-Acid Balance in Shaped Hydroisomerization Catalysts}

Pedro S. F. Mendes, ${ }^{*}$ João M. Silva, M. Filipa Ribeiro, Antoine Daudin, and Christophe Bouchy* 


\title{
Supporting Information
}

\author{
ChemCatChem
}

\section{Bifunctional intimacy and its interplay with metal-acid balance in shaped hydroisomerization catalysts}

Pedro S. F. Mendes ${ }^{\mathrm{a}, \mathrm{b}^{*}}$, João M. Silva ${ }^{\mathrm{a}, \mathrm{c}}$, M. Filipa Ribeiro ${ }^{\mathrm{a}}$, Antoine Daudin ${ }^{\mathrm{b}}$, Christophe Bouchy ${ }^{\mathrm{b} *}$

aCentro de Química Estrutura and Departamento de Engenharia Química, Instituto Superior Técnico, Universidade de Lisboa, Av. Rovisco Pais, 1049-001 Lisboa, Portugal

'bIFP Energies nouvelles, Rond-point de l'échangeur de Solaize, BP 3, 69360 Solaize, France

${ }^{c} A D E Q-I S E L$, Instituto Superior de Engenharia de Lisboa, Instituto Politécnico de Lisboa, R. Cons. Emídio Navarro, 1959-007 Lisboa, Portugal

* pedro.f.mendes@tecnico.ulisboa.pt; christophe.bouchy@ifpen.fr ; +33 (0)4 37702860

DOI: $10.1002 /$ cctc. 202000624

\section{Table of contents}

Electron probe micro analysis.

n-Hexadecane hydroisomerization. .3

Dual-function kinetic model. .5

References... .6 


\section{Electron probe micro analysis}

a)

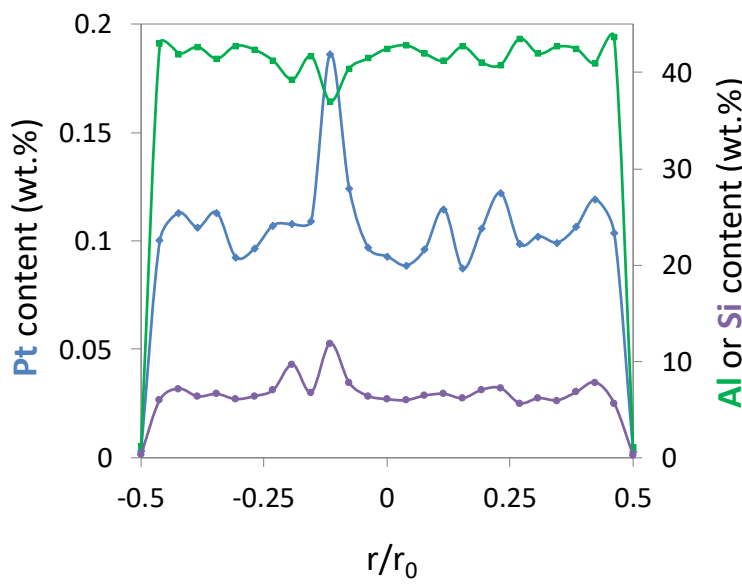

b)

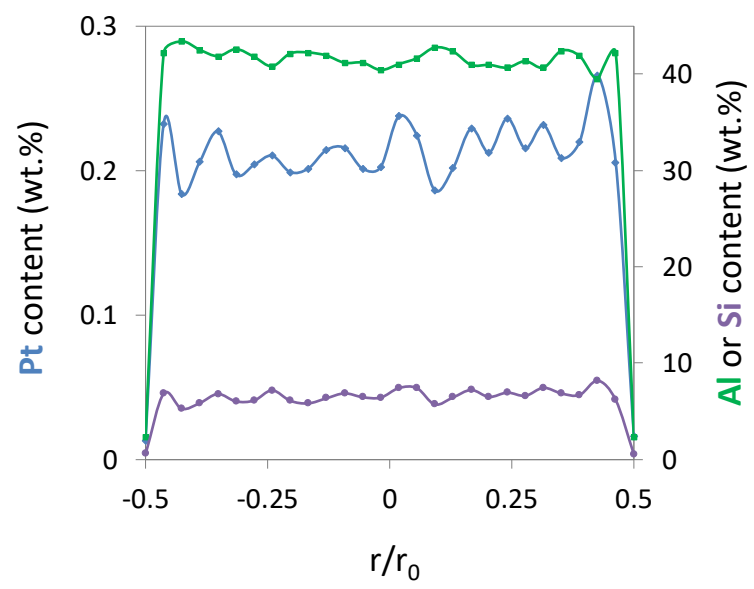

Figure S1: Average electron probe microanalysis profiles of $\mathrm{Al}$ (red), Si (purple), and Pt (blue) along the diameter of the extrudate for a) $0.11 \mathrm{Pt} / \mathrm{HUSY}+\mathrm{Al}_{2} \mathrm{O}_{3}$ and b) $0.25 \mathrm{Pt} / \mathrm{HUSY}+\mathrm{Al}_{2} \mathrm{O}_{3}$. Full ordinates scale: $100 \%$ for $\mathrm{Al}, 50 \%$ for $\mathrm{Si}$, and a) 0.2 and b) $0.5 \%$ for Pt. Reproduced from [1].

a)

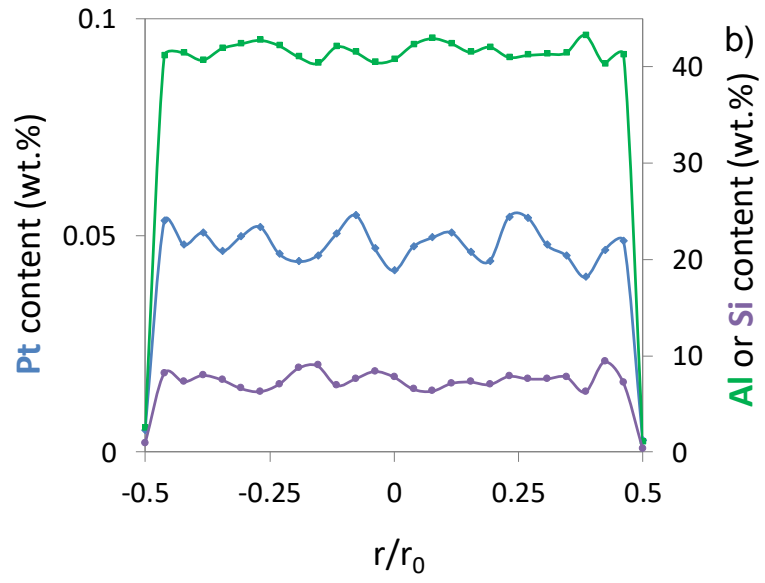

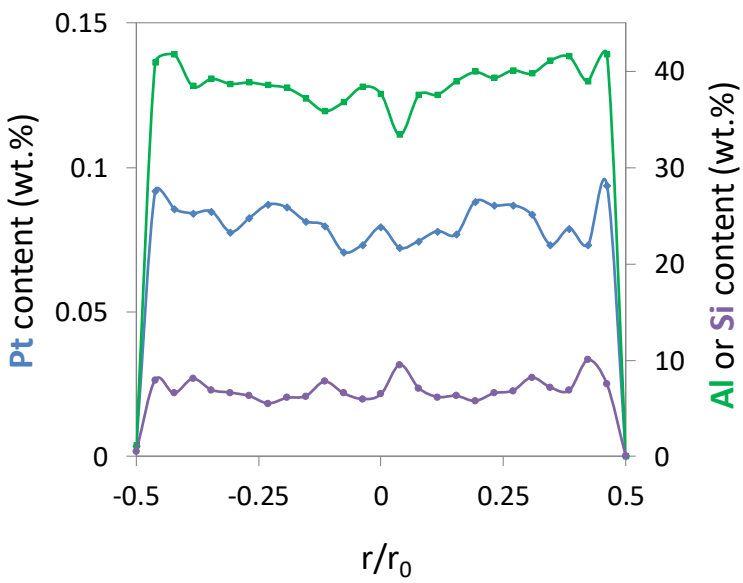

c)

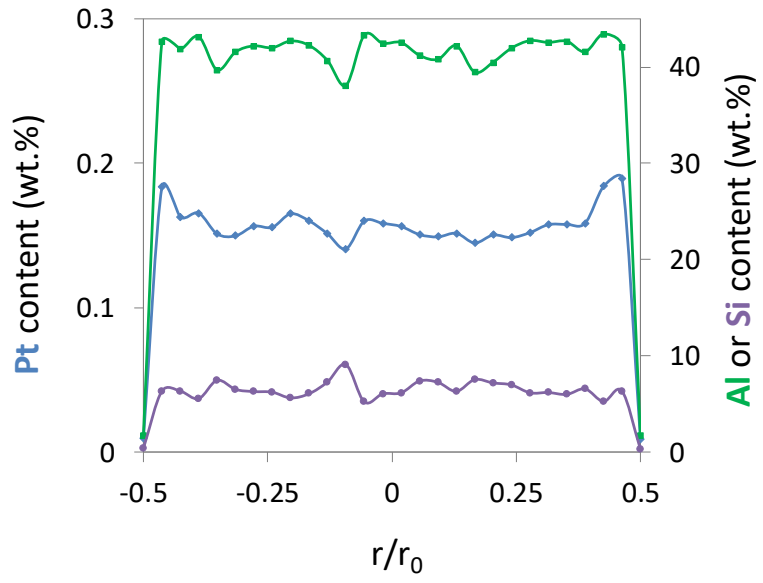

Figure S2: Average electron probe microanalysis profiles of $\mathrm{Al}$ (green), Si (purple), and Pt (blue) along the diameter of the extrudate for a) $0.04 \mathrm{Pt} / \mathrm{Al}_{2} \mathrm{O}_{3}+\mathrm{HUSY}$, b) $0.07 \mathrm{Pt} / \mathrm{Al}_{2} \mathrm{O}_{3}+\mathrm{HUSY}$, and c) $0.18 \mathrm{Pt} /$ $\mathrm{Al}_{2} \mathrm{O}_{3}+\mathrm{HUSY}$. 


\section{n-Hexadecane hydroisomerization}
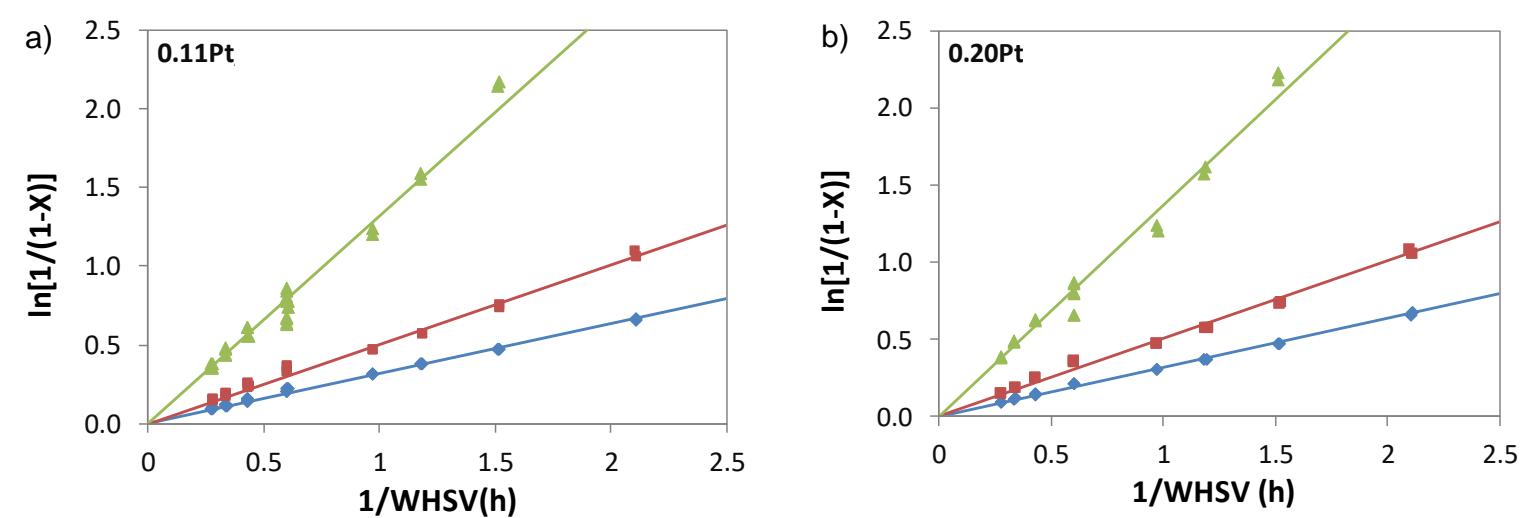

Figure S3: First-order plot for the consumption of $n-\mathrm{C}_{16}$ at $483 \mathrm{~K}(\diamond), 488 \mathrm{~K}(\square)$, and $498 \mathrm{~K}(\Delta)$ over $\mathrm{Pt} / \mathrm{HUSY}+\mathrm{Al}_{2} \mathrm{O}_{3}$ catalysts ${ }^{[1]}$. Symbols stand for experimental data and lines for fitting results. The reaction was carried out at $1.1 \mathrm{MPa}$ total pressure and a molar $\mathrm{H}_{2}$ to $n$ - $\mathrm{C}_{16}$ ratio of 10 .
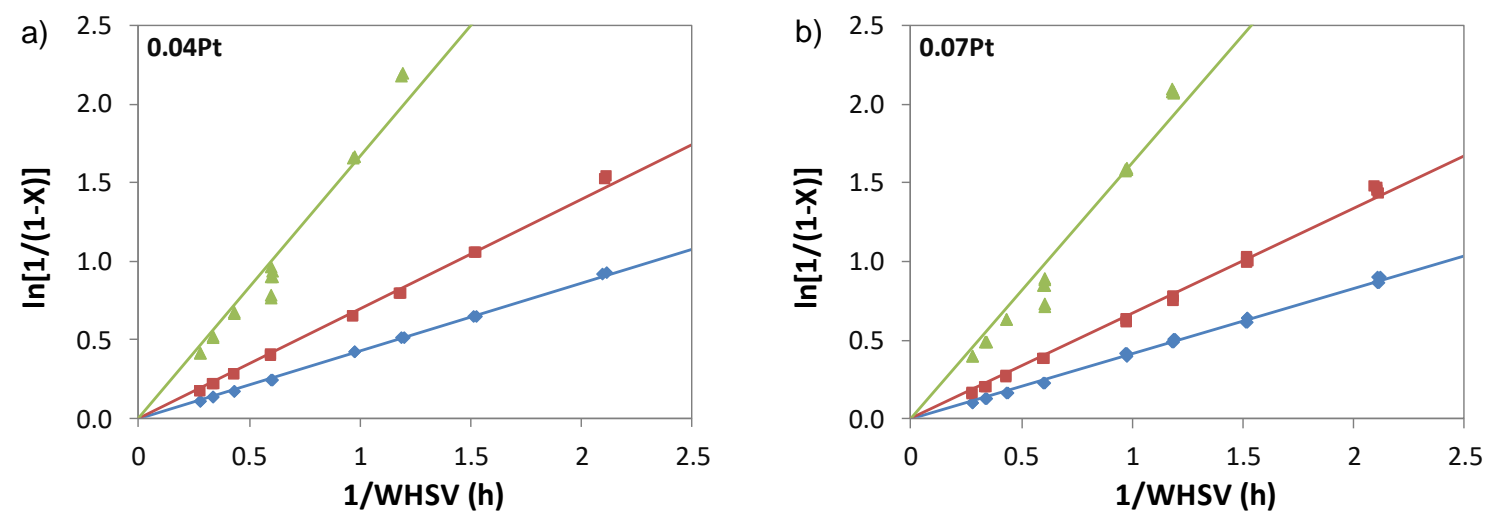

Figure S4: First-order plot for the consumption of $n-\mathrm{C}_{16}$ at $483 \mathrm{~K}(\diamond), 488 \mathrm{~K}(\square)$, and $498 \mathrm{~K}(\triangle)$ over $\mathrm{Pt} / \mathrm{Al}_{2} \mathrm{O}_{3}+\mathrm{HUSY}$ catalysts. Symbols stand for experimental data and lines for fitting results. The reaction was carried out at $1.1 \mathrm{MPa}$ total pressure and a molar $\mathrm{H}_{2}$ to $n-\mathrm{C}_{16}$ ratio of 10 . 

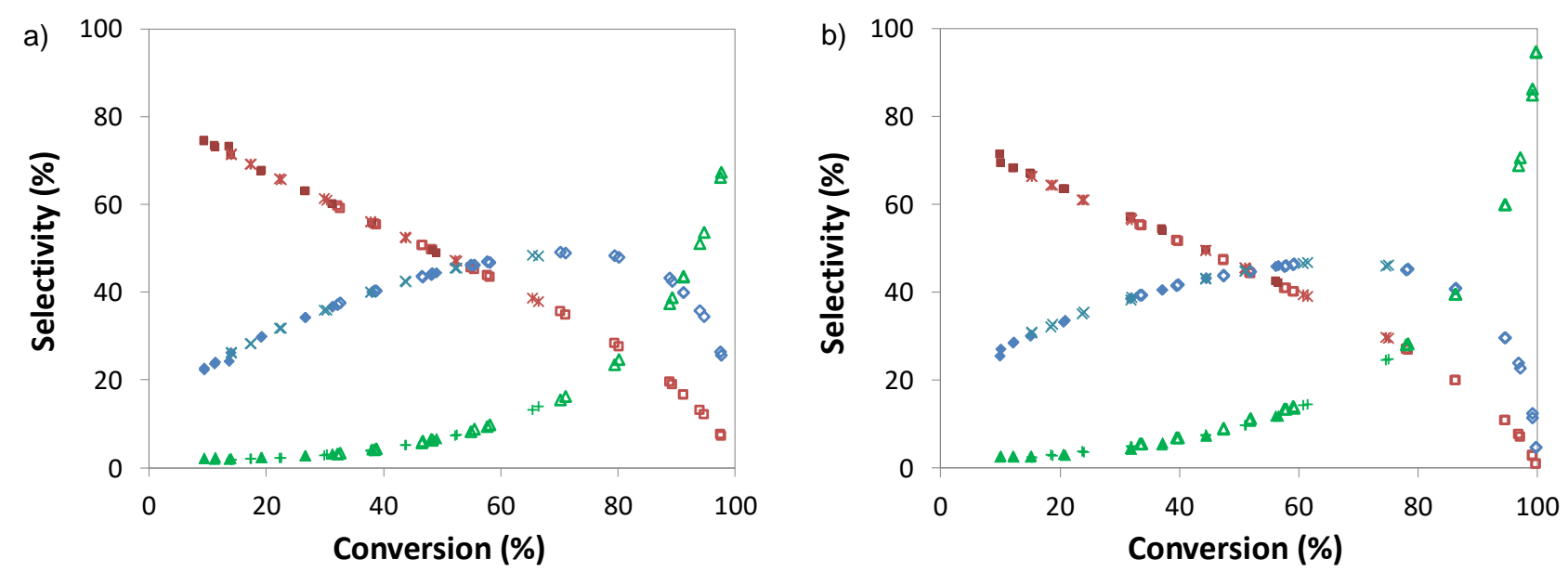

Figure S5: Monobranched $(\square)$ and multibranched $(\diamond) \mathrm{C}_{16}$ isomers, and cracking $(\Delta)$ products selectivity as function of conversion at $483 \mathrm{~K}$ (closed symbols), $488 \mathrm{~K}$ (cross symbols), and $498 \mathrm{~K}$ (open symbols), for a) $0.25 \mathrm{Pt} /\left(\mathrm{HUSY}+\mathrm{Al}_{2} \mathrm{O}_{3}\right){ }^{[1]}$ and b) $0.18 \mathrm{Pt} / \mathrm{Al}_{2} \mathrm{O}_{3}+\mathrm{HUSY}$.

Table S1: Apparent activation energy for $n$-hexadecane hydroconversion, assuming a $1^{\text {st-order }}$ kinetics.

\begin{tabular}{cc}
\hline Catalyst & Activation energy $\left(\mathrm{kJ} \mathrm{mol}^{-1}\right)$ \\
\hline $0.11 \mathrm{Pt} / \mathrm{HUSY}+\mathrm{Al}_{2} \mathrm{O}_{3}$ & 191 \\
$0.25 \mathrm{Pt} / \mathrm{HUSY}+\mathrm{Al}_{2} \mathrm{O}_{3}$ & 196 \\
$0.04 \mathrm{Pt} / \mathrm{Al}_{2} \mathrm{O}_{3}+\mathrm{HUSY}$ & 180 \\
$0.07 \mathrm{Pt} / \mathrm{Al}_{2} \mathrm{O}_{3}+\mathrm{HUSY}$ & 182 \\
$0.18 \mathrm{Pt} / \mathrm{Al}_{2} \mathrm{O}_{3}+\mathrm{HUSY}$ & 195 \\
\hline
\end{tabular}




\section{Dual-function kinetic model}

Table S2: Parameters for $Y_{i-C 16, m a x}$ (Eq. 1) determined by fitting catalytic descriptors results to the dualfunction kinetic model ${ }^{[2]}$.

\begin{tabular}{lcc}
\hline Catalyst series & $\begin{array}{c}\mathrm{Y} \\
(\%)\end{array}$ & $\begin{array}{c}\boldsymbol{\varepsilon} \\
\left(\mathbf{1 0 ^ { 3 }}\right)\end{array}$ \\
\hline $\mathrm{Pt} / \mathrm{HUSY} \mathrm{Al}_{2} \mathrm{O}_{3}$ & 62.3 & 1.9 \\
$\mathrm{Pt} / \mathrm{Al}_{2} \mathrm{O}_{3}+\mathrm{HUSY}$ & 58.3 & 1.8 \\
\hline
\end{tabular}




\section{References}

[1] P. S. F. Mendes, J. M. Silva, M. F. Ribeiro, A. Daudin, C. Bouchy, J. Ind. Eng. Chem. 2018, 62, 72-83.

[2] P. S. F. Mendes, J. M. Silva, M. F. Ribeiro, P. Duchêne, A. Daudin, C. Bouchy, AlChE J. 2017, $63,2864-2875$. 